\title{
Comparison between a wax/volatile oil mixture and vegetable butters in a long-lasting make-up formula: A rheological and structural study compared to product performance ${ }^{\text {is }}$
}

\author{
Charlène Hubert ${ }^{1,2}$, Cristelle Meriadec ${ }^{1}$, Pascal Panizza ${ }^{1}$, Franck Artzner ${ }^{1, *}$ \\ and Hélène de Clermont-Gallerande ${ }^{2, *}$ \\ ${ }^{1}$ Univ. Rennes, CNRS, IPR (Institut de Physique de Rennes)-UMR 6251, 263, Avenue Général Leclerc, 35700 Rennes, France \\ 2 Chanel Parfums Beauté, Recherche Beauté et Innovation, 8, Rue du Cheval Blanc, 93500 Pantin, France
}

Received 31 March 2020 - Accepted 20 July 2020

\begin{abstract}
The long-lasting make-up was created to avoid migration of the product on the skin throughout the day. Currently, the formulation technology most commonly used to obtain it is based on the use of filmforming agents with volatile oils. However, with the growing trend in natural cosmetics, petroleum-based volatile compounds are increasingly being abandoned. The objective of this study is to determine whether a mixture of plant-based butters can be chosen to replace a mixture of volatile oil and synthetic wax in a long-lasting eyeshadow. Initial comparisons were made between two jojoba butters and a wax/volatile oil mixture in order to identify the best candidate to replace the latter. Then, the best candidate was incorporated into formula and finished formulas were compared using sensory evaluation, rheology and X-ray scattering. The results show that it is possible to preserve texture, rheological properties and structural organization of a formula by replacing a wax/oil mixture with vegetable butters. However, this does not mean that the formulas will behave the same on the eyelids over time. This work illustrates the real complexity faced by formulators when they must replace one raw material with another while guaranteeing the durability of all the product's properties. This challenge is more relevant today as consumer demand for products based on natural ingredients is growing.
\end{abstract}

Keywords: formulation / long-lasting eyeshadow / volatile oil / jojoba butters

\begin{abstract}
Résumé - Comparaison entre un mélange cire/huile volatile et des beurres d'origine végétale dans une formule de maquillage longue-tenue: étude rhéologique et structurale comparée à la performance du produit. Le maquillage longue-tenue a été créé afin d'éviter la migration du produit sur la peau au cours de la journée. Actuellement, la technologie de formulation la plus utilisée pour en obtenir est basée sur l'utilisation d'agents filmogènes avec des huiles volatiles. Cependant, avec la tendance croissante des cosmétiques naturels, les composés volatils d'origine pétrolière sont de plus en plus délaissés. L'objectif de cette étude est de déterminer si un mélange de beurres d'origine végétale peut être choisi pour remplacer un mélange d'huile volatile et de cire synthétique dans une ombre à paupières longue-tenue. De premières comparaisons ont été réalisées entre deux beurres de jojoba et un mélange cire/huile volatile dans le but d'identifier le meilleur candidat pour remplacer ce dernier. Puis, le meilleur candidat a été incorporé en formule et les formules finies ont été comparées en utilisant l'évaluation sensorielle, la rhéologie et la diffusion des rayons X. Les résultats montrent qu'il est possible de conserver la texture, les propriétés rhéologiques et l'organisation structurale d'une formule en remplaçant un mélange cire/huile volatile par des beurres végétaux. Toutefois, cela ne signifie pas que les formules se comporteront de la même façon sur les paupières au fil du temps. Ce travail illustre la réelle complexité à laquelle sont confrontés les formulateurs lorsqu'ils doivent remplacer une matière
\end{abstract}

\footnotetext{
it Contribution to the Topical Issue "Lipids and Cosmetics / Lipides

et cosmétiques".

*Correspondences: franck.artzner@univ-rennes1.fr;

helene.declermontgallerande@chanel.com
} 
première par une autre tout en garantissant la pérennité de toutes les propriétés du produit. Ce défi est d'autant plus pertinent aujourd'hui car la demande des consommateurs pour des produits à base d'ingrédients naturels est croissante.

Mots clés : formulation / ombre à paupières longue-tenue / huile volatile / beurres de jojoba

\section{Introduction}

Make-up consumers often admit it, many of them have already had the bad experience of make-up (eyeshadow, foundation, lipstick) that is applied onto the skin in the morning and disappears over the course of the day. To avoid this type of inconvenience, color cosmetic products with longlasting claims were created several decades ago. This claim is characterized by the fact that the film deposited by the make-up product will last for more than $8 \mathrm{~h}$ after application. First for the lips, then for the complexion and eyes, crystallized lipidbased make-up products that are long-lasting are now omnipresent on the cosmetic market (Bui and Coleman-Nally, 2017). To characterize the behavior of a make-up product over time, the cosmetics industry uses two main types of evaluation: the analysis of high-resolution images and the visual evaluation of the make-up area by a trained person who assigns a score to several criteria such as color, homogeneity, migration or diffusion at different times of the day.

Currently, the most widespread formulation way for obtaining long-lasting make-up is the use of film-forming agents, due to their ability to produce a continuous film on a substrate with very good adhesion and flexibility properties. The most commonly used film-forming agents for cosmetic applications are those based on silicone and acrylate, but there are also many others of synthetic origin and, increasingly, of natural origin (Bailey, 1971; Bentley, 1999; Rathke and Hudson, 2006). Nevertheless, whatever their origin and whether used alone or in combination, film formers are in most cases used with at least one volatile oil. Among them, the most common are volatile silicones such as cyclomethicone and short-chain alkanes such as isododecane (de ClermontGallerande, 2006). For example, for the formulation of eyeshadows, two main routes are used: the dry route and the wet route. In the first, the volatile oil is evaporated during the manufacturing process to obtain a powder, whereas in the wet method, the oil evaporates after each application to the skin.

Nevertheless, with the era of natural cosmetics, which are more environmentally friendly, volatile compounds of petroleum origin seem to be delivered to an uncertain future. Indeed, in addition to want new and better performing products, consumers want more and more products based on natural and biodegradable ingredients (Duprat-de-Paule et al., 2018). Another reason for wanting to get rid of it comes from the intrinsic characteristic of volatility. Products that contain volatile oils require hermetic packaging which generates additional costs but also risks of drying the product which can affect the product's effectiveness. However, volatile oils can reach up to forty percent by mass in some formulas. Therefore, when they are removed, the consequences are important in terms of texture, make-up results and effectiveness. Thus, one of the current objectives of the cosmetics industry is to find an alternative to these volatile oils of petroleum origin while maintaining these criteria.

One option would have been to replace the volatile oils with non-volatile oils, but the latter severely degrade longlasting performance. Another option could have been to replace petroleum volatile oil with a volatile oil of vegetable origin, but this option does not solve the constraints related to airtightness. Thus, another alternative has been chosen which consists in replacing not the volatile oil alone but the mixture of volatile oil and wax. Indeed, in addition to containing volatile oil, long-lasting make-up products with a greasy texture also contain high-melting fats such as waxes. If the volatile oil that is liquid is removed alone, the product becomes a real pebble that is very friable and difficult to spread. Therefore, by also removing a solid wax, this compensates for the texture.

To replace the mixture of volatile oil and wax, research has focused on raw materials of vegetable origin with an intermediate butter-like texture. Finally, jojoba esters (Simmondsia chinensis) were chosen for several reasons. On the one hand, jojoba esters are composed of monounsaturated fatty acids and alcohols containing mainly 18 to 24 carbon atoms (Busson-Breysse et al., 1994). Their chemical structures are very similar to those of the wax esters naturally produced by human skin in sebum, as can be seen in Figure 1. This likeness of chemical structure gives them excellent hydration properties and their cis configuration makes them widely used as nongreasy emollients (Lecomte, 2009; Juncan et al., 2019). On the other hand, jojoba esters are very thermally stable compounds, their Oxidation Stability Index (OSI) is more than fifteen times higher than that of refined jojoba oil, respectively $675 \mathrm{~h}$ versus $35 \mathrm{~h}$ (Mouloungui et al., 2006). Finally, in addition to their vegetable origin, they are biodegradable.

Concerning the make-up products, it was decided to work on eyeshadows. Indeed, although lipsticks are today at the heart of many scientific studies (de Clermont-Gallerande, 2006; Munawiroh et al., 2017; Pan and Germann, 2019; Kang et al., 2020) because it is a flagship product in make-up, studies on eyeshadows are much rarer and could be a real lever for innovation and differentiation to revitalize eye products. In addition, eyeshadows play on the perception of eye size and bring depth to the eyes. In this regard, the illusionary effects of wearing eyeshadows have been scientifically investigated on several occasions (Morikawa et al., 2015; Muto et al., 2019).

This article focuses on the similarities and differences between vegetable butters and a volatile oil/wax mixture in terms of texture, rheological properties, organization at the microscopic and molecular scales, and performance (wear on the eyelids). The comparisons were carried out for the raw materials alone, but also after incorporation into a formula body of a long-lasting make-up formula. 
$\mathrm{CH}_{3}-\left(\mathrm{CH}_{2}\right)_{7}-\mathrm{CH}=\mathrm{CH} \backslash\left(\mathrm{CH}_{2}\right)_{\mathrm{m}}-\stackrel{\mathrm{O}}{\mathrm{C}}-\mathrm{O}-\left(\mathrm{CH}_{2}\right)^{-}-\left(\mathrm{CH}_{2}\right)_{n}^{-}, \mathrm{CH}=\mathrm{CH} \backslash\left(\mathrm{CH}_{2}\right)_{7}-\mathrm{CH}_{3}$

(a)

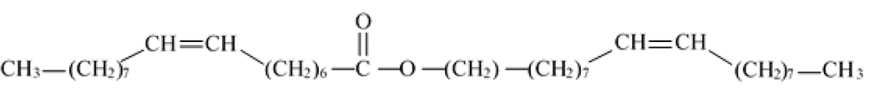

(b)

Fig. 1. Chemical formulas of (a) jojoba esters and (b) wax esters naturally produced by the skin.

\section{Material and methods}

\subsection{Raw materials and process}

In the mixture of volatile oil and wax, the oil used is isodododecane, which is a volatile solvent with a flash point of $51^{\circ} \mathrm{C}$ and the wax is a Fischer-Tropsch high melting point wax with a melting point of $93{ }^{\circ} \mathrm{C}$. Isododecane was obtained from IMCD (UK) and wax from Sasol Performance Chemical (Germany). Table 1 gives more details on the physico-chemical specifications of these raw materials. These two ingredients were mixed together to form a binary. The proportions of the binary are the same as those used in a finished formula of long-lasting eyeshadow, i.e. $68 \%$ isododecane and $32 \%$ wax $(\mathrm{w} / \mathrm{w})$. The two raw materials were mixed at high temperature $\left(\mathrm{T}=95^{\circ} \mathrm{C}\right)$ to reach the melting point of the wax, under stirring with a deflocculator and a Turbotest laboratory mixer (VMI Linxis Group, France) at $320 \mathrm{rpm}$ for 15 minutes. Special safety precautions were taken because the flash point of isododecane is lower than the melting point of wax. The solvent loss due to evaporation was compensated by adding isododecane to the mix at the end of the formulation. Then the binary was cooled to $0{ }^{\circ} \mathrm{C}$ for 30 minutes and let to stand for $24 \mathrm{~h}$ at room temperature.

The vegetable butters selected to replace the binary of volatile oil and wax are two jojoba esters which have been named butter A and butter B. Butters are distinguished by the length of their carbon chains, resulting in different melting points and textures. The butter $\mathrm{A}$ has a melting range between 47 and $51{ }^{\circ} \mathrm{C}$ and has a soft and creamy texture while the butter $\mathrm{B}$ has a melting range between 56 and $60{ }^{\circ} \mathrm{C}$ and a very firm texture. This information is summarized in Table 1. These butters were obtained from jojoba oil and hydrogenated jojoba oil which were melted and inter-esterified in the presence of a catalyst. The two butters were compared one by one to the binary, but butter blends were also made. The first is a mixture of butter $A$ and butter B in the proportions $75 \%$ and $25 \%(w / w)$ respectively and the second is a $50 \%(\mathrm{w} / \mathrm{w})$ mixture between the two butters. The mixtures of jojoba esters were carried out at $60{ }^{\circ} \mathrm{C}$ under stirring with a deflocculator and a Turbotest laboratory mixer (VMI Linxis Group, France) at $200 \mathrm{rpm}$ for 15 minutes and then cooled following the same protocol as described above for the wax and volatile oil binary. Butters alone also followed this protocol in order to have identical thermal histories for more reliable comparisons.

\subsection{Eyeshadow formulas}

The binary of volatile oil and wax was compared to jojoba esters alone but also incorporated into the formula.
A long-lasting eyeshadow formula containing the volatile oil and wax was used as a positive control. This is a creamy, anhydrous eyeshadow formula mainly composed of isododecane $(23.4 \mathrm{w} \%)$, synthetic wax $(11 \mathrm{w} \%)$, a film-forming agent and pigments. The formula was carried out hot $\left(95^{\circ} \mathrm{C}\right)$ under stirring with a deflocculator and a Turbotest laboratory mixer (VMI Linxis Group, France) at $500 \mathrm{rpm}$ then cooled according to the same protocol described for the raw materials.

Based on this positive control formula, the volatile oil and wax have been replaced by jojoba butters in the same proportions as the sum of the two ingredients in the binary, i.e. $34.4 \mathrm{w} \%$. This new jojoba butters formula was compared to the reference formula (positive control). The formulation protocol is the same as the positive control formula except that the formula was only heated to $65^{\circ} \mathrm{C}$ and no solvent was added at the end to as there was no need to compensate for evaporation.

In addition to these two formulas (the positive control with volatile oil and wax and the new formula with jojoba esters), a formula that is not long-lasting was defined as a negative control. This is a gel formula with a gloss effect mainly composed of emollients, plasticizers, gelling agents and pigments.

These three eyeshadows formulas were evaluated according to their texture, their rheological properties, their structural organization and their long-lasting performance.

\subsection{Sensory evaluations}

Changing raw materials that have a high mass percentage in a formula has several consequences, particularly in terms of make-up result, texture and effectiveness. In this study, these last two attributes were assessed in a sensory manner.

\subsubsection{Tactile evaluation of texture}

The evaluation of the texture of the raw materials and complete formulas was carried out by touch after spreading on the back of the hand. This evaluation was carried out $48 \mathrm{~h}$ after formulation. The attributes assessed were softness, ease of spreading and stickiness.

This is not a complete sensory evaluation as is customary to do internally for the development of new formulas because this is an upstream study. Nevertheless, it is a matter of verifying that the texture is not too strongly impacted by the replacement of the wax and volatile oil binary with jojoba butters for a non-expert.

\subsubsection{Visual evaluation of long-lasting performance}

Long lasting performance was evaluated only for finished eyeshadow formulas and not for raw materials or binary mixtures. The efficacy department has a great deal of expertise in formula efficiency evaluation, and it is based on their work that the long-lasting evaluation of the formulas was established for this study.

This evaluation was done in three times: at $\mathrm{t}_{0}$ immediately after application, $\mathrm{t}_{0}+4 \mathrm{~h}$ and finally $\mathrm{t}_{0}+8 \mathrm{~h}$. The criterion assessed was the migration of the product which is characterized by the fact that the product marks the folds, $i$. $e$. it accumulates over time in the wrinkles and or fine lines of the eyelids. 
Table 1. Physical/chemical characteristics of the wax, oil and vegetable butters used in this study.

\begin{tabular}{|c|c|c|c|c|c|c|}
\hline Raw materials & INCI name & Origin & Appearance & Melting point $\left({ }^{\circ} \mathrm{C}\right)$ & Density $\mathrm{g} / \mathrm{cm}^{3}$ & Molecular weight $\mathrm{g} / \mathrm{mol}$ \\
\hline Volatile oil & Isododecane & Petroleum & Colorless liquid & & 0.749 & 170.34 \\
\hline
\end{tabular}

INCI: International Nomenclature of Cosmetic Ingredient.

As for the texture, the formulas were applied and evaluated $48 \mathrm{~h}$ after application. Each formula was tested on three volunteers and evaluated qualitatively on a scale ranging from product that migrates very strongly to product that does not migrate at all.

\subsection{Experimental techniques and methods}

Sensory evaluations were compared with instrumental characterizations in order to identify whether correlations exist between in-vivo evaluations and in-vitro measurements.

\subsubsection{Optical microscopy}

Optical microscopy observations were performed using the IX70 inverted microscope (Olympus, Japan) in polarized mode and a DP-soft camera (Camedia digital camera, C4040 Zoom, Olympus, Japan) connected to a computer. In order to facilitate microscopic observation in polarized light, pigments and mother-of-pearl have been removed from the finished formulations. Samples were prepared by depositing a small quantity onto a glass microscope slide. The formula was pressed with a glass cover slip to ensure a sample thin enough for polarized light microscopy. The polarizer and analyzer were not in a fixed cross orientation and could be rotated. The samples were observed with a x10 objective (CPlanFI, Olympus, Japan) and a x40 objective (LCPlanFI, Olympus, Japan). Images were obtained using Cam2Com digital camera control software (Sabsik, US).

\subsubsection{X-ray scattering}

The structural organization of the samples was also evaluated by X-ray scattering with a homemade setup. X-ray scattering results were collected with a Pilatus $300 \mathrm{~K}$ (Dectris, Switzerland), mounted on a microsource X-ray generator GeniX 3D (Xenocs, France) operating at $30 \mathrm{~W}$. The monochromatic $\mathrm{CuK}_{\alpha}$ radiation was of $\lambda=1.541 \AA$. The results were recorded in a reciprocal space $q=(4 \pi \cdot \sin \theta) / \lambda$ in a range of repetitive distances from 0.01 to $1.72 \AA^{-1}$. The pigments in the samples analyzed by X-ray scattering were removed. This is because iron oxides (the source of many pigments) absorb the wavelength of copper and re-emit fluorescence, resulting in an attenuated signal with a very intense background that is difficult to interpret. The samples were introduced into $1.5 \mathrm{~mm}$ quartz capillaries, then centrifuged and sealed with candle wax. For the analysis, they have been introduced in a capillary holder accommodating 19 capillaries at controlled temperature. Each capillary was probed at two y-positions to check the homogeneity of the sample. The analyses were carried out following a temperature ramp from $20^{\circ} \mathrm{C}$ to $95^{\circ} \mathrm{C}$ every $5^{\circ} \mathrm{C}$ with an exposure time per point of 10 minutes. The objective of this analysis was twofold, firstly it allowed us to identify a melting range for raw material and binary mixtures and secondly to obtain X-ray signature of the finished products at $35^{\circ} \mathrm{C}$, as this is the temperature estimated to be the skin surface temperature (Mi Lee et al., 2018). For this study, the focus was on the type of structure (long range order) by Small Angle X-ray Scattering (SAXS) and on the type of packing (short range order) by Wide Angle $\mathrm{X}$-ray Scattering(WAXS). The results were collected by a homemade program and analyzed by the Igor Pro 7.0 software (Wavemetrics, US).

\subsubsection{Rheology}

The rheological properties of the samples were evaluated using a controlled-stress rheometer (Discovery HR 2, TA Instruments, France) equipped with a Peltier plate and a heating parallel plate called UHP (Upper Heated Plate). The UHP is a temperature option designed to eliminate vertical temperature gradients in samples. The diameter of the UHP is $40 \mathrm{~mm}$. Prior to analysis, the Peltier plate and UHP geometry were preheated to $35^{\circ} \mathrm{C}$ for 30 minutes. A black cover supplied with the UHP limits temperature dissipation and prevents evaporation during measurements. Samples were deposited on the Peltier plate and the UHP geometry was going down on the deposits until it came into contact with them while maintaining a $1 \mathrm{~mm}$ air gap. Samples were equilibrated for 5 minutes after loading before measurement. Data analyses were performed using TRIOS ${ }^{\circledR} 4.3$ software (TA Instruments, France) provided with the rheometer. Under these conditions, two types of tests were conducted: flow tests and oscillation tests.

\subsubsection{Flow tests}

First, the samples were subjected to two flow experiments. The first one consisted in applying a fixed shear rate of $0.01 \mathrm{~s}^{-1}$ for 10 minutes and measuring the average viscosity. This preliminary test gives a first idea of the time dependence of the sample. That is to say, it allows both to know if the sample needs a certain time to reach equilibrium when subjected to a constant shear rate and also to identify if the sample is thixotropic, i.e. if the viscosity of the sample decreases with time at constant shear rate.

The second experiment consists of applying a range of shear rates from 0.1 to $10^{-5} \mathrm{~s}^{-1}$. Flow is deliberately imposed from high to low shear rates because there is a greater risk of artifacts at low shear rates. The highest shear rate cannot be higher than $0.1 \mathrm{~s}^{-1}$ because above this rate the sample exits 
the air gap. This type of experiment makes it possible to identify the behavior under flow of the samples, i.e. to know the evolution of the viscosity when the shear rate increases. For example, if the samples are shear-thinning, this means that their viscosity decreases as the shear rate increases. In addition to the viscosity evolution as a function of the shear rate, the yield stress was also determined. This is the stress that must be applied for the sample to start flowing. For the analysis of the results, we processed the data after applying the Rabinowicz correction and then the Herschel-Bulkley model directly from TRIOS ${ }^{\circledR}$.

The Rabinowicz correction is necessary to correct overestimated results when the rheology experiments took place with a parallel plate geometry such as UHP. Indeed, for a coneplane geometry, due to the conical shape, the height of the air gap is lower at the center, therefore the shear of the sample is constant over the entire surface of the geometry. On the contrary, when the geometry is flat, there is a shear velocity gradient, the shear rate varies across the plate from zero in the center to a maximum at the rim. However, the strain and shear rate reported by TRIOS ${ }^{\circledast}$ are those at the rim, therefore there is an overestimation of the values obtained. The HerschelBulkley model that was used to determine the yield stress of the samples incorporates the elements of a Newtonian, a Power law and a Bingham fluid and is governed by the constitutive equation (Herschel and Bulkley, 1926):

$$
\sigma=\sigma_{y}+k \dot{\gamma}^{n}
$$

where $\sigma$ is the shear rate, $\sigma_{y}$ the yield stress, $\mathrm{k}$ the consistency index, $\dot{\gamma}$ the shear rate and $n$ the power law index.

- If $\sigma<\sigma_{y}$ the sample behaves as a solid;

- If $\sigma>\sigma_{y}$ the sample behaves as a liquid.

For $n<1$, the sample is shear-thinning whereas for $n>1$, the sample is shear-thickening. The sample is a Newtonian fluid when $n=1$ and $\sigma_{y}=0$ This model describes many materials exhibiting a yield stress and it can be used as a general-purpose model for many material systems.

\subsubsection{Oscillation tests}

In addition to the flow experiments, the samples were also subjected to oscillation tests in order to evaluate their viscoelastic behavior. Dynamic viscoelasticity allows identification of the structure of the sample at rest for low amplitude oscillations. The principle is to induce a sinusoidal shear deformation or stress in the sample and measure the resultant deformation or stress response. In this study, the viscoelastic properties of the samples were obtained by recording the storage modulus G' (solid-like contribution) when samples were subjected to a stress ramp ranging from 1 to $2000 \mathrm{~Pa}$ and at a constant frequency and temperature of $1 \mathrm{~Hz}$ and $35^{\circ} \mathrm{C}$ respectively. Oscillations of small amplitude performed at a frequency of $1 \mathrm{~Hz}$ allowed to compare the mean value of the storage modulus and the linear viscoelastic regime for each sample.

\section{Results and discussion}

The results of this study show that jojoba butters can be a good substitute for wax and volatile oil mixture in terms of texture, rheological properties and structural organization.
However, the durability of the product performance is not necessarily guaranteed.

\subsection{Raw materials: jojoba butters as a good substitute for wax/oil mixture?}

Characterizing a heterogeneous material as an anhydrous make-up product based on crystallized fat is essential to understand its properties. In such products, parameters such as the quantity of crystallized fats, their homogeneity, their solubility in oil directly impact the size and morphology of the crystals. And it is these impacted parameters which themselves influence the properties of the product, such as its sensory (Abidh, 2017) or rheological properties (Marangoni and Wesdorp, 2012). For this reason, the reference binary of wax and volatile oil was compared to jojoba esters, focusing on the evaluation of texture, which was compared with melting ranges, microscopic observations and rheological properties as can be seen in Table 2.

The reference binary has a rather soft texture, is easy to spread and not sticky. The texture of butter A is similar to that of the reference binary but is slightly softer. Conversely, butter $\mathrm{B}$ has a firm texture and is difficult to spread. Butters mixtures logically have an intermediate texture between that of butter A and butter B but are difficult to distinguish. Finally, it is the mixtures of jojoba butters that have a texture closest to that of the reference binary.

Determination of the melting range of the samples by $\mathrm{X}$-ray scattering shows that the melting range is not correlated with texture for this study. Indeed, the reference binary has the highest melting range, between 75 and $80^{\circ} \mathrm{C}$ (due to the high melting point of the synthetic wax) but it is the butter B that has been evaluated as having the firmest texture and the most difficult to spread on the skin. The parameters that impact the texture of a product are multiple. For example, it has been shown (Braipson-Danthine and Deroanne, 2004) that the texture and more particularly the hardness of several binary vegetable oil blends was impacted by the solid fat content but also by the microstructure. Actually, it was shown that for three mixtures with same solid fat content, the microstructure observed under microscopy was different, reflecting the texture.

By observing our samples under a microscope in polarized light, it can be noted that the shapes of the crystals are the same for all, i.e. very small spherical crystals $(\sim 10 \mu \mathrm{m})$ and needles more or less grouped in clusters, but their size differs. The average size of the needle-shaped crystals is about $40 \mu \mathrm{m}$ for butter A as opposed to double for butter B. The crystals of the 75/ $25 \%$ mixture (butter A/butter B) have an average size of $40 \mu \mathrm{m}$ as for butter A alone while those of the $50 \%$ butters mixture have an intermediate average size of $60 \mu \mathrm{m}$. However, the average crystal size of the reference binary is much smaller, since on average the needles measure $20 \mu \mathrm{m}$. For jojoba butters, the size of the needle-shaped crystals appears to be proportional to the texture, i.e. the larger the needles in the microstructure, the harder the sample. By contrast, this finding is not applicable to the reference binary with wax and volatile oil since the needles are the small ones and yet its texture is not the softest.

A research team (Blake et al., 2014) studied the elastic properties of wax and oil mixtures as a function of the shape of 


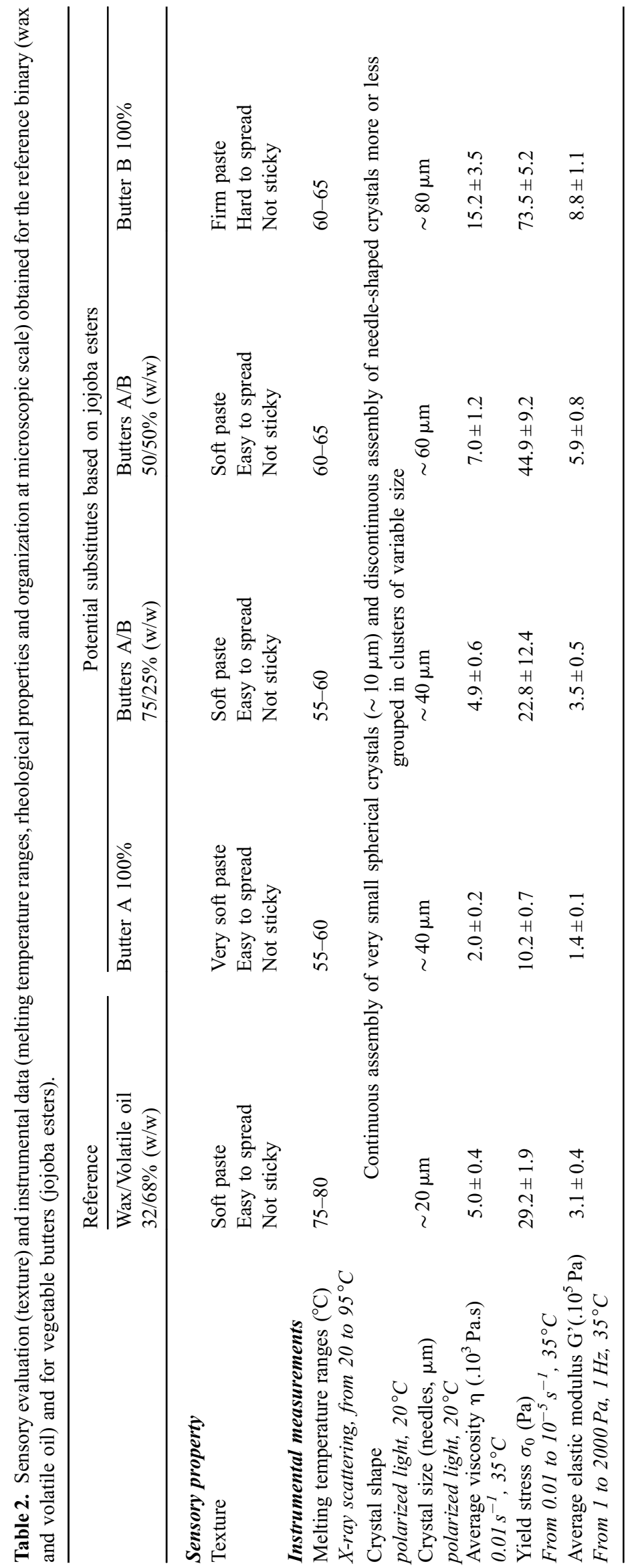

Page 6 of 12 


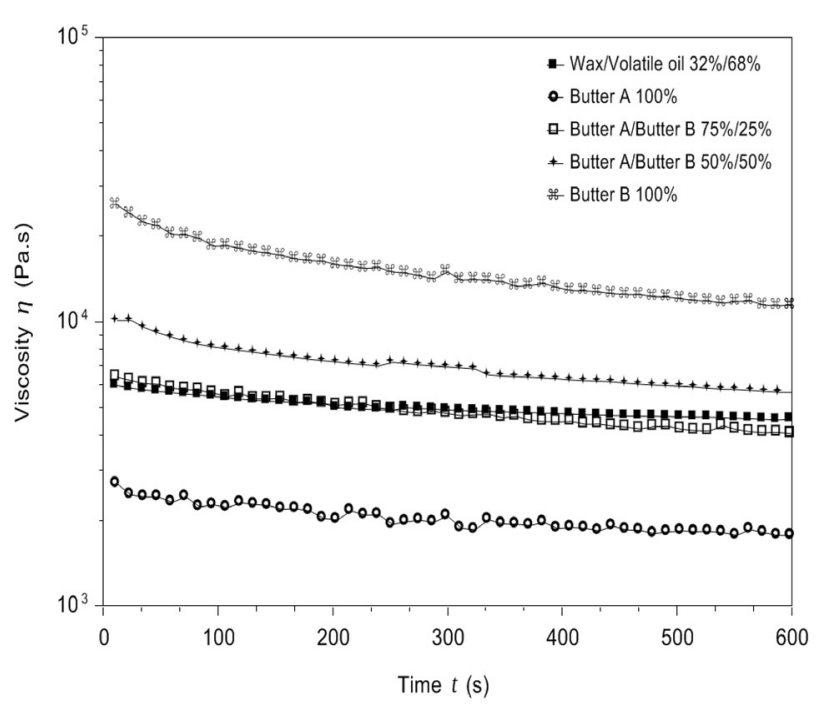

(a)

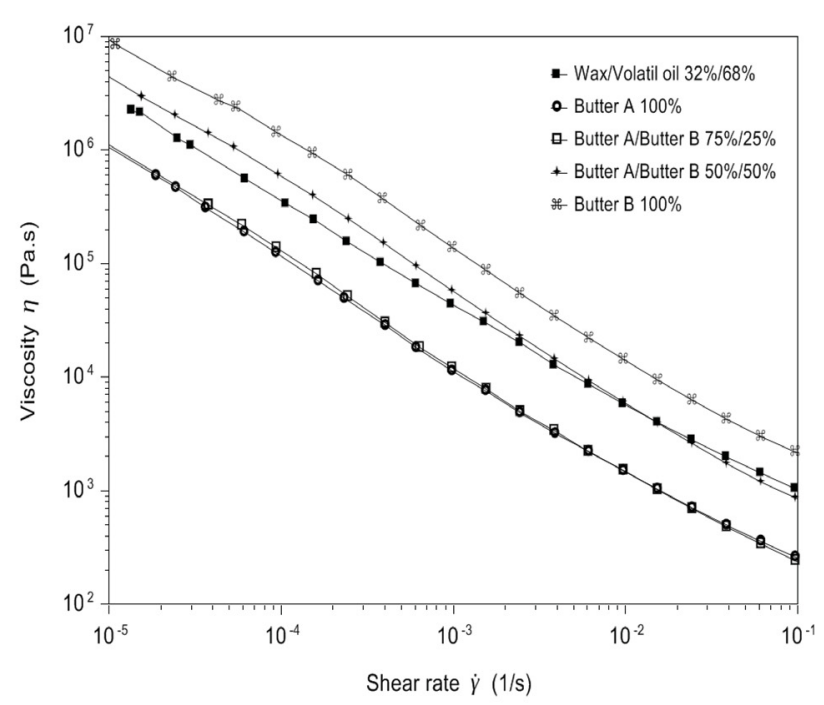

(b)

Fig. 2. Viscosity $\eta(\mathrm{Pa})$ of the reference binary wax + volatile oil as well as vegetable butters (butter $\mathrm{A}$, butter $\mathrm{A} / \mathrm{butter} \mathrm{B}$ at $75 \% / 25 \%$ (w/w), butter A/butter B at $50 \% / 50 \%(\mathrm{w} / \mathrm{w})$, butter B) obtained for (a) a fixed shear rate of $0.01 \mathrm{~s}^{-1}$ for 10 minutes at $35^{\circ} \mathrm{C}$ and for (b) a range of shear rates from 0.1 to $10^{-5} \mathrm{~s}^{-1}$ at $35^{\circ} \mathrm{C}$. Results obtained after application of the Rabinowicz correction.

the crystals. Needle-shaped crystals have been shown to provide better elastic properties and greater mixture strength while spherical crystals provide better oil retention. In our samples, both forms of crystals are present, only the size of the needles differs. The question was whether the size of the crystals could have an impact on the classical rheological properties of the sample. As with the melting range and needleshaped crystals size, the rheological properties evaluated appear to be correlated with texture for all jojoba butter samples (Tab. 2). A firm butter such as butter B has a high melting range, is composed of crystals in the form of large needles, and has an average viscosity, a yield stress and an average elastic modulus higher than a soft butter such as butter A. Thus, the microstructure impacts the rheological properties of jojoba butter samples through the size of the needle-like crystals.

From now on, if the comparison of rheology results is no longer made between jojoba but between each of the butters and the reference binary, it appears that it is the mixtures of butters that have the closest results to those of the reference binary, whether for the flow tests (Fig. 2) or the oscillation test (Fig. 3).

For the flow test at a fixed shear rate $\left(0.01 \mathrm{~s}^{-1}\right)$ at $35^{\circ} \mathrm{C}$, the average viscosity of the reference binary is $5.0 \pm 0.4 .10^{3} \mathrm{~Pa}$.s versus $4.9 \pm 0.6 .10^{3}$ Pa.s (Tab. 2) for the $75 / 25 \%$ mixture (butter A/butter B), which is very close. This is confirmed by analyzing their curves shown in Figure 2a, since they overlap at least during the first 5 minutes. It is also important to note that the viscosity decreases over time (thixotropy) for all jojoba butter-based samples whereas this is not the case for the reference binary. Although the samples are not all timedependent, they have in common that they are all shearthinning. Indeed, in the flow test over a shear rate range from 0.1 to $10^{-5} \mathrm{~s}^{-1}$ at $35^{\circ} \mathrm{C}$, visible in Figure $2 \mathrm{~b}$, all samples have their viscosity decreasing with increasing shear rate. The shearthinning curve that is closest to that of the reference binary is that

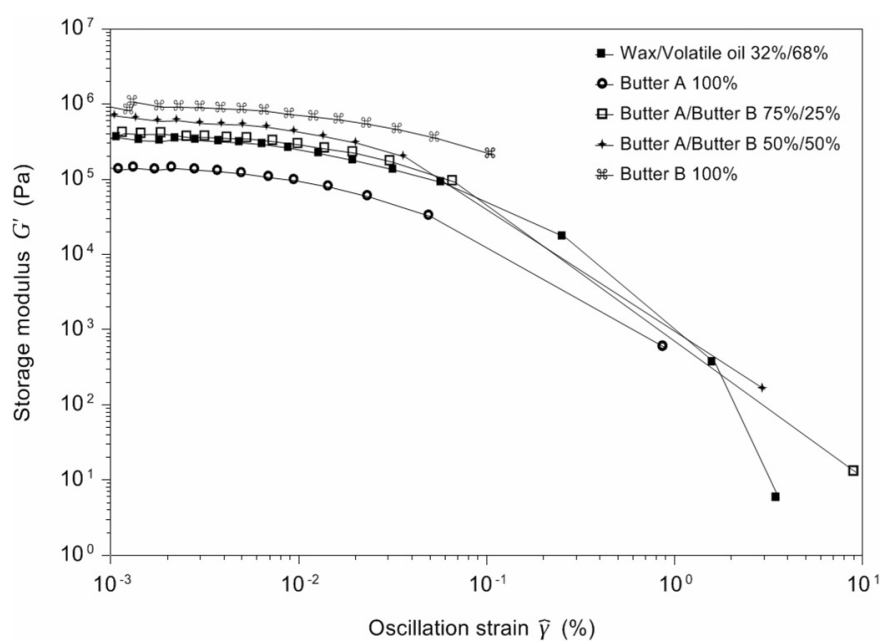

Fig. 3. Elastic modulus G' $(\mathrm{Pa})$ of the reference binary wax + volatile oil as well as vegetable butters (butter A, butter A/butter B at $75 \%$ / $25 \%(\mathrm{w} / \mathrm{w})$, butter $\mathrm{A} /$ butter B at $50 \% / 50 \%(\mathrm{w} / \mathrm{w})$, butter B) obtained for a stress ramp ranging from 1 to $2000 \mathrm{~Pa}$ at $1 \mathrm{~Hz}$ and $35^{\circ} \mathrm{C}$.

of the $50 \%$ jojoba butter mixtures. After applying the Rabinowicz correction and then the Herschel-Bulkley model, the determination of the yield stress of the samples allows to identify that it is the $75 / 25 \%$ mixture (butter A/butter B) that has the yield stress closest to that of the reference binary, respectively $22.8 \pm 12.4 \mathrm{~Pa}$ and $29.2 \pm 1.9 \mathrm{~Pa}$ (Tab. 2). Finally, concerning the oscillation test which imposes a stress ramp from 1 to $2000 \mathrm{~Pa}$, at $35^{\circ} \mathrm{C}$, if the mean value of the elastic modulus in the linear viscoelastic range is compared for each sample, it is once again the $75 / 25 \%$ mixture (butter A/butter B) which has the value closest to that of the reference binary. The average elastic modulus is $3.1 \pm 0.4 .10^{5} \mathrm{~Pa}$ for the reference binary and 
Table 3. Summary of sensory and instrumental comparisons between the reference binary (wax and volatile oil) and vegetable butters (jojoba esters). Each cross in a column means that this sample has the characteristic corresponding to the line closest to that of the reference binary.

\begin{tabular}{|c|c|c|c|c|}
\hline & \multicolumn{4}{|c|}{ Potential substitutes based on jojoba esters } \\
\hline \multicolumn{5}{|l|}{ Sensory property } \\
\hline Texture & & $\mathrm{x}$ & $\mathrm{x}$ & \\
\hline \multicolumn{5}{|l|}{ Instrumental measurements } \\
\hline $\begin{array}{l}\text { Melting temperature ranges }\left({ }^{\circ} \mathrm{C}\right) \\
X \text {-ray scattering, from } 20 \text { to } 95^{\circ} \mathrm{C}\end{array}$ & & & $\mathrm{x}$ & $\mathrm{x}$ \\
\hline polarized light, $20^{\circ} \mathrm{C}$ & $\mathrm{x}$ & $\mathrm{x}$ & & \\
\hline $\begin{array}{l}\text { Crystal size (needles, } \mu \mathrm{m}) \\
\text { polarized light, } 20^{\circ} \mathrm{C}\end{array}$ & & & & \\
\hline $\begin{array}{l}\text { Average viscosity } \eta\left(.10^{3} \text { Pa.s }\right) \\
0.01 \mathrm{~s}^{-1}, 35^{\circ} \mathrm{C}\end{array}$ & & $\mathrm{x}$ & & \\
\hline $\begin{array}{l}\text { Yield stress } \sigma_{0}(\mathrm{~Pa}) \\
\text { From } 0.01 \text { to } 10^{-5} \mathrm{~s}^{-1}, 35^{\circ} \mathrm{C}\end{array}$ & & $\mathrm{x}$ & & \\
\hline
\end{tabular}

$3.5 \pm 0.5 \cdot 10^{5} \mathrm{~Pa}$ for the $75 / 25 \%$ mixture (butter A/butter B) (Tab. 2). It should be noted that the curves of these two samples, shown in Figure 3, overlap in almost the entire linear viscoelastic range, i.e. from 2 to $40 \mathrm{~Pa}$, which corresponds to a percentage deformation ranging from $10^{-3}$ to $10^{-2} \%$.

The objective of this first study was to identify the best candidate to replace the wax and volatile oil binary. Considering the different characterizations whether sensory or instrumental, as shown in Table 3, it is the mixture of 75/ $25 \%$ jojoba butters (butter A/butter B) that has the characteristics closest to those of the reference binary. Therefore, it is the latter that has been chosen to be incorporated into the eyeshadow formula (positive control) in place of the wax and volatile oil.

\subsection{In formula: comparison of physical properties and performance of finished products}

The new eyeshadow formula based on the $75 / 25 \%$ mixture of jojoba esters was compared to the reference long-lasting formula: the positive control, and to the reference formula that is not long-lasting: the negative control. The parameters evaluated were the same as for the study of raw materials and binary mixtures, with the exception that the wear of the eyeshadows was also evaluated, as well as the type of structure and the type of packing determined by X-ray scattering as can be seen in Table 4.

The textures of the three samples are very similar, i.e. they are rather soft; they soften on contact with the skin and are easy to spread. Only the negative control formula appears slightly sticky.

With reference to rheological properties, it can be noted that, as desired, the new formula based on jojoba butters and the old formula based on wax and volatile oil have very similar values (Tab. 4). The average viscosity at $0.01 \mathrm{~s}^{-1}$ and $35^{\circ} \mathrm{C}$ of the positive control is $5.5 \pm 0.08 .10^{4} \mathrm{~Pa}$.s and that of the new formula is $5.1 \pm 0.4 .10^{4} \mathrm{~Pa}$.s. As for raw materials, it is possible to see in Figure $4 \mathrm{a}$ a time dependence (thixotropy) for the new formula (and for the negative control formula). The three samples are also shear-thinning as can be seen in Figure $4 \mathrm{~b}$ but with a different behavior for the negative control formula which suggests that it flows more easily. This is confirmed with the yield stress values since for the negative control formula it is only $59.9 \pm 0.9 \mathrm{~Pa}$ compared to almost 4 times more for the new formula and more than 5 times more for the positive control formula (Tab. 4). As regards the elastic properties of the samples, once again the new formula has its viscosity versus percent strain curve, shown in Figure 5, very close to that of the positive control formula. Moreover, the averages of their elastic modulus in the linear viscoelastic range are very close.

Therefore, it seems that the incorporation into the formula with the other raw materials had no impact on the proximity of the rheological properties of the two samples. This means that it is really the lipids (in one case, oil and wax and in the other, butters) that have a significant impact on the classical rheological properties of the sample. As the texture of the new formula and the old one (positive control) are also very similar, by impacting the rheological properties, lipids also impact the texture. This again underlines the relationship between sensory properties and fatty ingredients as recently discussed for a lipstick study (de Clermont-Gallerande et al., 2018).

Afterwards, the question was, do two eyeshadow formulas with almost similar texture and rheological properties necessarily have the same behavior on the eyelids over the course of a day? For the samples studied, the answer is no. Indeed, the new formula with jojoba butters shows a slight migration in the eyelid wrinkles contrary to the positive control formula. But as can be seen in Figure 6, the migration of the new formula is not as significant as for the negative control formula. 
Table 4. Sensory evaluation (texture and wear on the eyelids after $8 \mathrm{~h}$ ) and instrumental data (rheological properties and organization at the microscopic and molecular scales) obtained for the positive control (long-lasting formula), the negative control (formula that migrates very quickly into the eyelids) and the new formula based on the mixture of jojoba esters $(75 / 25 \% \mathrm{w} / \mathrm{w}$ butter A/butter B).

\begin{tabular}{|c|c|c|}
\hline Positive control & New formula to compare & Negative control \\
\hline $\begin{array}{l}\text { Long-lasting formula with } \\
\text { wax and volatile oil }\end{array}$ & $\begin{array}{l}\text { New formula with jojoba esters } \\
\text { without wax or volatile oil }\end{array}$ & $\begin{array}{l}\text { Not long-lasting formula without } \\
\text { wax, butter or volatile oil }\end{array}$ \\
\hline
\end{tabular}

\section{Sensory properties}

Texture

Eyeshadow wear after $8 \mathrm{~h}$

Instrumental measurements

Average viscosity $\eta\left(.10^{4} \mathrm{~Pa} . \mathrm{s}\right)$

$0.01 \mathrm{~s}^{-1}, 35^{\circ} \mathrm{C}$

Yield stress $\sigma_{0}(\mathrm{~Pa})$

From 0.01 to $10^{-5} \mathrm{~s}^{-1}, 35^{\circ} \mathrm{C}$

Average elastic modulus $\mathrm{G}^{\prime}\left(.10^{5} \mathrm{~Pa}\right)$

From 1 to $2000 \mathrm{~Pa}, 1 \mathrm{~Hz}, 35^{\circ} \mathrm{C}$

Crystal shape

polarized light, $20^{\circ} \mathrm{C}$

Crystal size (needles, $\mu \mathrm{m}$ )

polarized light, $20^{\circ} \mathrm{C}$

Type of structure (SAXS)

and type of packing (WAXS)
Quite soft paste

Easy to spread

Not sticky

No migration

$$
5.5 \pm 0.08
$$

$304.7 \pm 23.5$

$3.3 \pm 0.3$

Not very cohesive clusters

of small crystals in needle shape

$\sim 10 \mu \mathrm{m}$

Lamellar structure

Orthorhombic packing
Soft paste

Easy to spread

Not sticky

Slight migration

$$
5.1 \pm 0.4
$$

$237.9 \pm 28.3$

$4.4 \pm 0.4$

Cohesive assembly of

large crystals in needle shape

$\sim 80 \mu \mathrm{m}$

Lamellar structure Orthorhombic packing
Soft paste

Easy to spread

Slightly sticky

Significant migration

$2.1 \pm 0.2$

$59.9 \pm 0.9$

$0.5 \pm 0.007$

No birefringence

Lamellar structure No short-range order

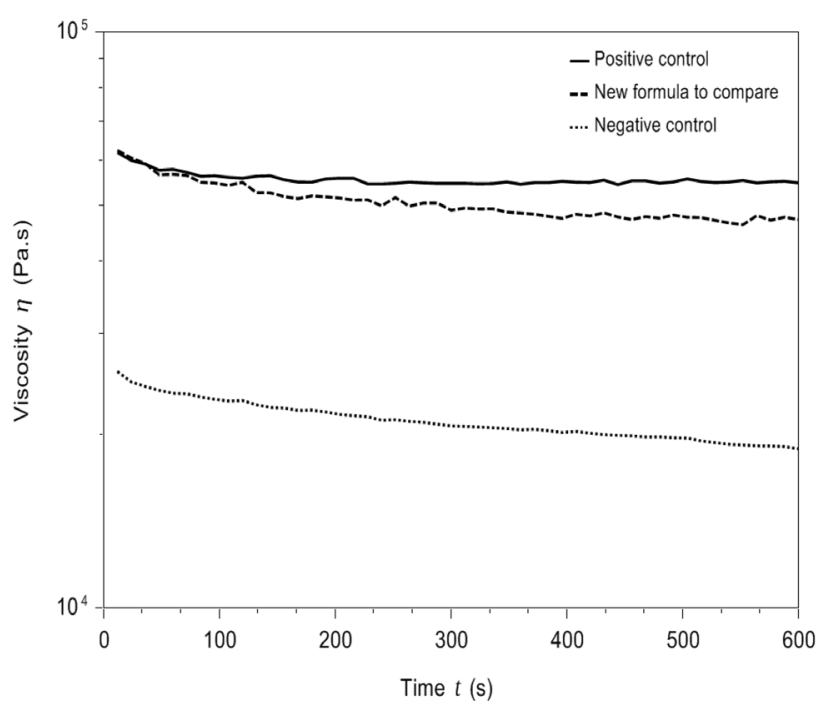

(a)

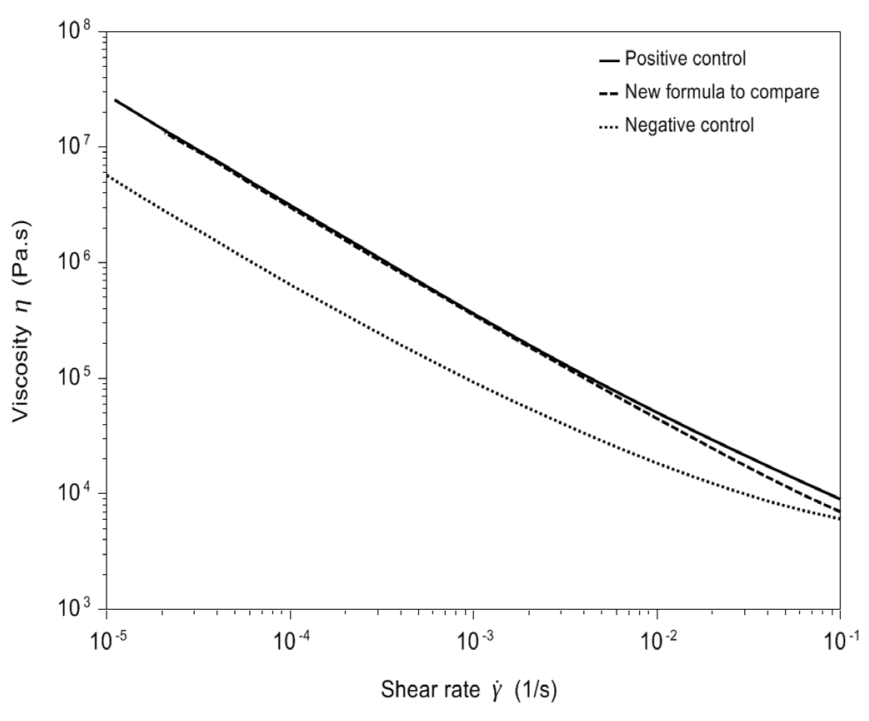

(b)

Fig. 4. Viscosity $\eta(\mathrm{Pa})$ of the positive control (long-lasting formula), the negative control (formula that migrates very quickly into the eyelids) and the new formula based on the mixture of jojoba esters $\left(75 / 25 \%\right.$ butter A/butter B w/w) obtained for (a) a fixed shear rate of $0.01 \mathrm{~s}^{-1}$ for 10 minutes at $35^{\circ} \mathrm{C}$ and for (b) a range of shear rates from $0.1 \mathrm{~s}^{-1}$ to $10^{-5} \mathrm{~s}^{-1}$ at $35^{\circ} \mathrm{C}$. Results obtained after application of the Rabinowicz correction.

Then, the challenge was to identify a type of characterization which makes it possible to discriminate the new formula (based on jojoba esters) from the old one (based on wax and volatile oil) like the results of wearing on the eyelids.

The X-ray scattering results, shown in Figure 7, identify the type of structure and the type of packing of the three samples. At small angles, the three samples have a lamellar structure but with a different characteristic distance. The first two peaks of the negative control formula are at $0.145 \AA^{-1}$ and $0.290 \AA^{-1}$ corresponding to a characteristic distance of $43 \AA$. For the new formula based on jojoba butters, the first two peaks are at $0.112 \AA^{-1}$ and $0.224 \AA^{-1}$ corresponding to a characteristic distance of $56 \AA$. Finally, for the positive control formula the first two peaks are at $0.099 \AA^{-1}$ and $0.199 \AA^{-1}$ 


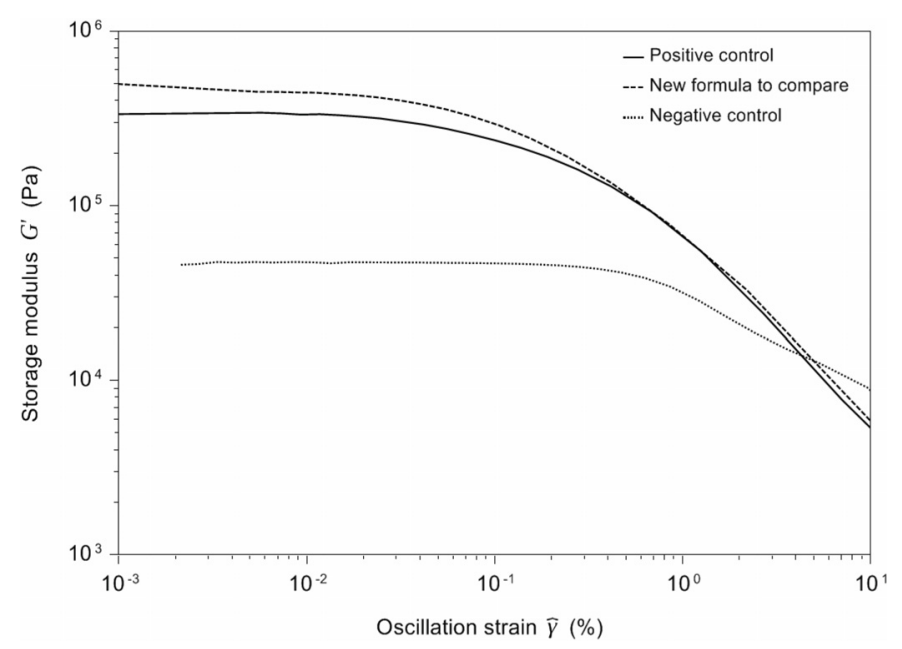

Fig. 5. Elastic modulus G' (Pa) of the positive control (long-lasting formula with wax and volatile oil), the negative control (formula that migrates very quickly into the eyelids without wax, butter or volatile oil) and the new formula based on the mixture of jojoba esters $(75 / 25 \%$ butter $\mathrm{A} /$ butter $\mathrm{B} \mathrm{w} / \mathrm{w}$ ) obtained for a stress ramp ranging from 1 to $2000 \mathrm{~Pa}$ at $1 \mathrm{~Hz}$ and $35^{\circ} \mathrm{C}$.

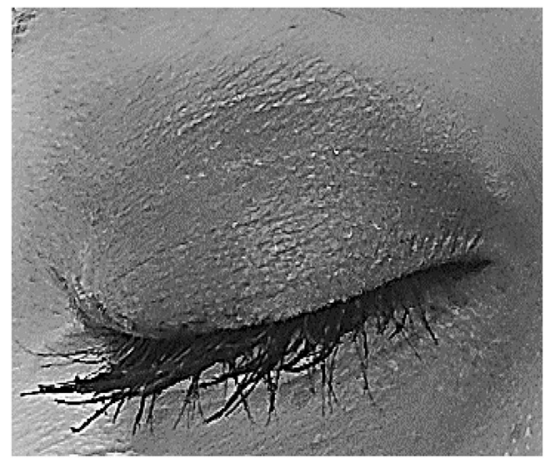

(a)

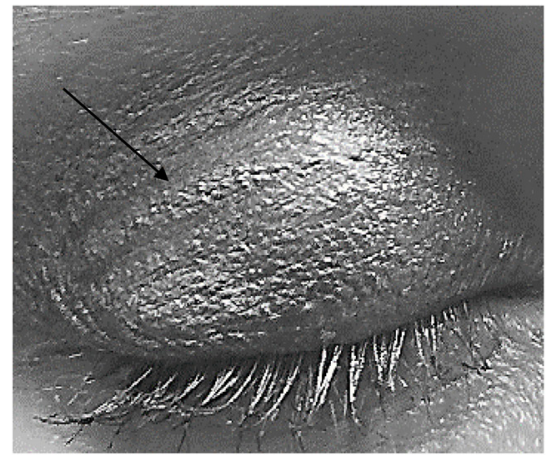

(b)

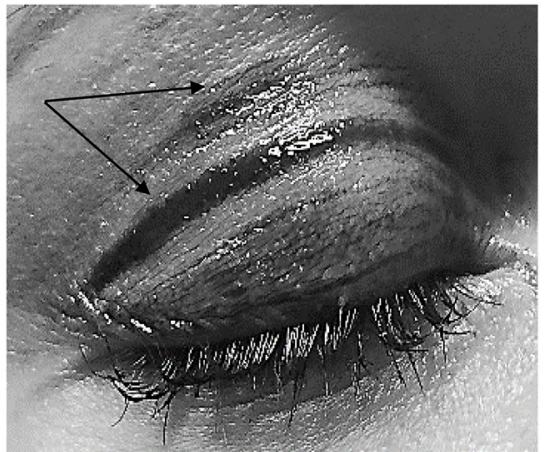

(c)

Fig. 6. Eyeshadow wear after $8 \mathrm{~h}$ on the eyelids for (a) the positive control (long-lasting formula with wax and volatile oil) (b) the new formula based on the mixture of jojoba esters $(75 / 25 \%$ butter A/butter B w/w) and (c) the negative control (formula that migrates very quickly into the eyelids without wax, butter or volatile oil). The arrows show the migration of the eyeshadow into the eyelid wrinkles.

corresponding to a characteristic distance of $63 \AA$. At wide angles, while the negative control formula shows no short-range order, the positive control formula and the new formula show orthorhombic packing (peaks at $1.53 \AA^{-1}$ and $1.69 \AA^{-1}$ ). This information on the structural organization of the samples is very interesting but does not clearly distinguish between the two formulas (the positive control formula and the new one) as they both have a lamellar structure and an orthorhombic packing.

Differences between the two eyeshadow formulas are visible in polarized light microscopy. Indeed, as shown in Figure 8, for either $\mathrm{x} 10$ or $\mathrm{x} 40$ magnification, the samples have different crystal sizes and microscopic organization. The negative control formula is not birefringent as it does not contain crystallized fats. The positive control formula has a lot of small needle-like crystals but seems not very cohesive, the whole is not continuous. Conversely, the new formula based on jojoba butters is composed of larger crystals and the set of crystals appears continuous and therefore more cohesive (Tab. 4, Fig. 8). Hence, polarized light optical microscopy brings first evidence that allows to distinguish the long-lasting formula with wax and volatile oil and the new formula with jojoba esters, like the wear on the eyelids. This difference in microstructure may be a first response to identify a correlation between in-vivo evaluation (wear on eyelids) and in-vitro measurement (microstructure observation under polarized light optical microscopy).

The difference in cohesion between the two formulas can be explained by the raw materials of which they are composed. The positive control formula contains a volatile oil. A study (Dufresne et al., 2006) has shown that when a solvent evaporates from a film deposited on a substrate, stresses appear in the film, generated by high capillary pressures related to air/ solvent menisci. Theses stresses cause the film to shrink. However, this shrinkage is frustrated by the adhesion which prevents the film from deforming freely. In addition to the adhesion, the cohesion of the film, its elastic modulus and thickness affect the film's ability to deform. If these stressed exceed the critical stress of the film, the film relaxes the 


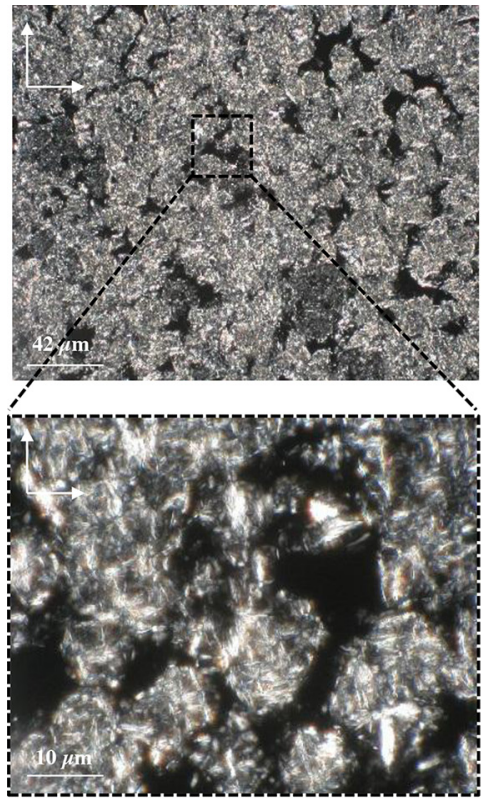

(a)

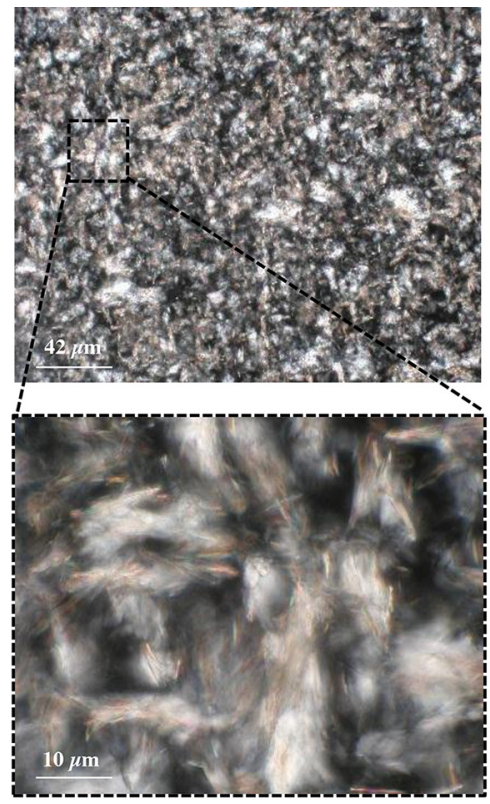

(b)

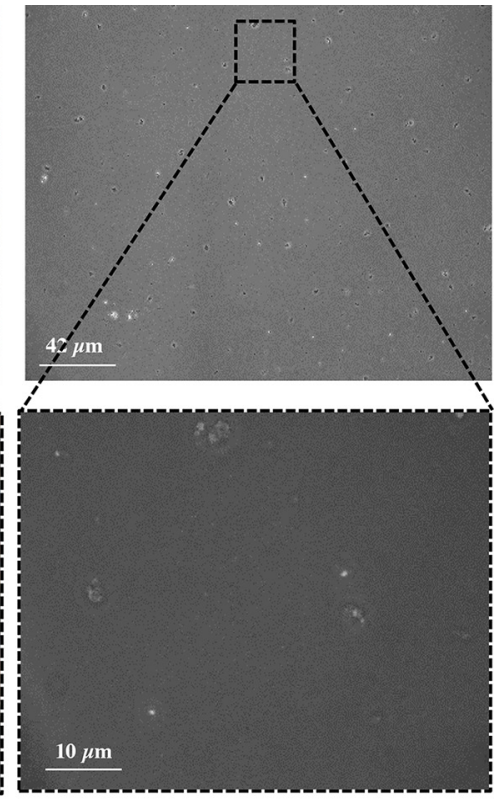

(c)

Fig. 8. Structural organization on a microscopic scale for (a) the positive control (long-lasting formula with wax and volatile oil) (b) the new formula based on the mixture of jojoba esters $(75 / 25 \%$ butter A/butter B w/w) and (c) the negative control (formula that migrates very quickly into the eyelids without wax, butter or volatile oil). The optical microscopy images were obtained under polarized light with cross-polarizers $\left( \pm 45^{\circ}\right)$ at $20^{\circ} \mathrm{C}$ and with magnifications of $\mathrm{x} 10$ (top microscopic images) and $\mathrm{x} 40$ (bottom microscopic images).

stresses by creating cracks. This phenomenon of cracking with drying is favored for a thick film with a low elastic modulus, not very cohesive but adhesive.

A long-lasting eyeshadow (with volatile oil) after application is subject to internal stress (the volatile oil evaporation) and external stress (the deformation of the eyelids during blinking). Thus, a less cohesive eyeshadow formula such as the positive control formula (which is made less cohesive by the evaporation of volatile oil) may be better suited to the deformations associated with eyelids blink through the formation of microcracks. While a highly cohesive formula (and not very adhesive to the skin) would tend to move as the eyelids blink towards the largest specific surface area, as here in the eyelid wrinkles. This difference in cohesion, illustrated in Figure 9, is highly visible when formulas of the positive control and of the negative control are spread on an inert support mimicking the skin (polyurethane elastomer), then dried for $8 \mathrm{~h}$ at $35^{\circ} \mathrm{C}$ and stretched by a factor of 2 for $10 \mathrm{~s}$. Therefore, in order to be long-lasting, the eyeshadow formula should not be too cohesive.

\section{Conclusion}

In a make-up formula, when the aim is to replace one raw material by another, it is necessary to identify the criteria on which it is not possible to compromise. By knowing the physical parameters that impact these criteria, it is possible to choose the best candidate to replace the old one based on experiments that evaluate these physical parameters. In this study it was shown that it is conceivable to replace a mixture of high melting wax and volatile oil with a mixture of jojoba butters because the textures and classical rheological properties are very similar (provided the right butters blend is chosen).

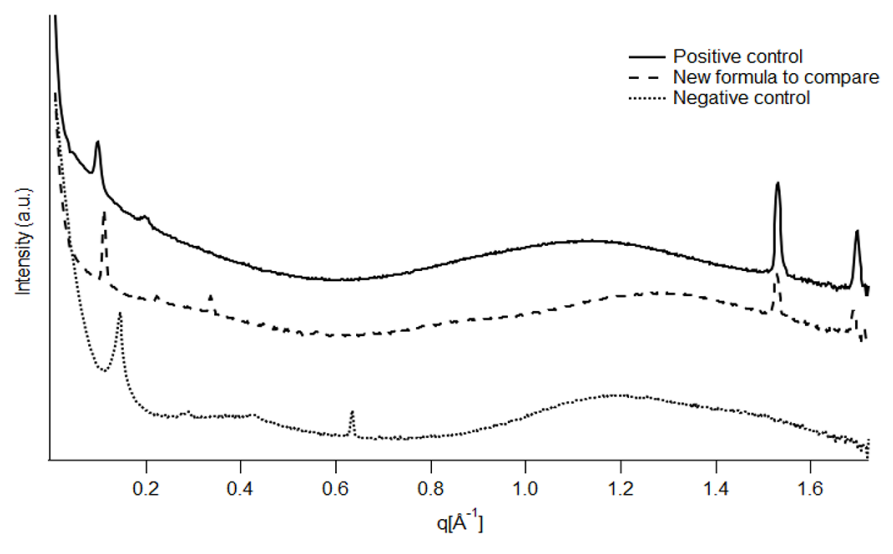

Fig. 7. X-ray scattering results of the positive control (long-lasting formula with wax and volatile oil), the negative control (formula that migrates very quickly into the eyelids without wax, butter or volatile oil) and the new formula based on the mixture of jojoba esters (75/ $25 \%$ butter $\mathrm{A} /$ butter B w/w) obtained for an analysis at $35^{\circ} \mathrm{C}$ with an exposure time per point of 10 minutes.

Nevertheless, when beyond make-up result and texture, product performance such as long-lasting effectiveness is sought as well, precautions must be taken. Indeed, it has been shown that the behavior on the eyelids of the formula based on wax and volatile oil was not the same over time as that of the new formula based on jojoba butters. This underlines the importance of volatile oil. In addition to have a role during formulation and spreading, it also plays a role after application during drying. Because by its evaporation, it implies a loss of cohesion of the formula which facilitates the formation of 

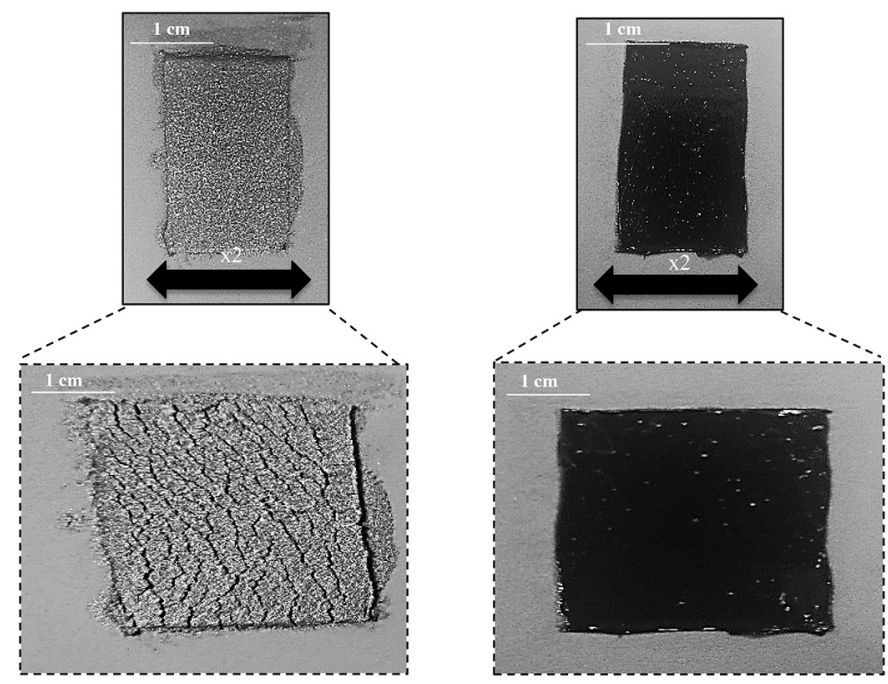

Fig. 9. Behavior of (a) positive control and (b) negative control after spreading $(\sim 100 \mu \mathrm{m})$ on a polyurethane mimicking the skin then dried for $8 \mathrm{~h}$ at $35^{\circ} \mathrm{C}$ and stretched by a factor of 2 for $10 \mathrm{~s}$. Cracks appear in the positive control formula while the negative control formula shows no cracks.

microcracks in the deposit. And these microcracks allow the formula to better adapt to the deformations to which it is subjected every $3 \mathrm{~s}$, i.e. the eyelids blink.

Afterwards, it would be interesting to imagine drying tests $\left(8 \mathrm{~h}\right.$ in a ventilated oven at $35^{\circ} \mathrm{C}$ ) of a long-lasting eyeshadow formula on different supports that would be subjected to a tensile test, varying the elasticity of the support, its roughness and also its chemistry, in order to identify to what extent these parameters impact the adhesion of the formula and the formation of these cracks after evaporation of the volatile oil. These tests would make it possible to correlate the appearance of microcracks with the drying of the product on inert supports (in-vitro) with the observed long wear of the product on the eyelids (in-vivo).

More generally, this study illustrates the real complexity that formulators are increasingly faced with when they have to replace one raw material with another while guaranteeing the durability of as many of the product's properties as possible.

\section{References}

Abidh S. 2017. Méthodologie d'ingénierie sensorielle pour la formulation de produits cosmétiques, application au rouge à lèvres. Thèse de doctorat NMT: 2017SACLA023.

Bailey ME. 1971. Polyurethane film formers. J Elastoplastics 3: 126-136.

Bentley J. 1999. Organic film formers. In: Lambourne R, Strivens TA, eds. Paint and surface coatings: Theory and practice, 2 nd ed. Amsterdam, NH: Elsevier.
Blake AI, Co ED, Marangoni AG. 2014. Structure and physical properties of plant wax crystal networks and their relationship to oil binding capacity. J Am Oil Chem Soc 91(6): 885-903.

Braipson-Danthine S, Deroanne C. 2004. Influence of SFC, microstructure and polymorphism on texture (hardness) of binary blends of fats involved in the preparation of industrial shortenings. Food Res Int 37(10): 941-948.

Bui HS, Coleman-Nally D. 2017. Film-forming technology and skin adhesion in long-wear cosmetics. In: Mittal KL, Etzler FM, eds. Adhesion in pharmaceutical, biomedical and dental fields. Beverly, MA: Scrivener Publishing LLC.

Busson-Breysse J, Farines M, Soulier J. 1994. Jojoba wax esters. J Am Oil Chem Soc 71(9): 999-1002.

de Clermont-Gallerande H. 2006. Évolution des corps gras utilisés dans la formulation des rouges à lèvres au cours des quinze dernières années. OCL 13: 322-325.

de Clermont-Gallerande H, Abidh S, Lauer A, Navarro S, Cuvelier G, Delarue J. 2018. Relations between the sensory properties and fat ingredients of lipsticks. OCL 25(5): D502.

Dufresne ER, Stark DJ, Greenblatt NA, et al. 2006. Dynamics of fracture in drying suspensions. Langmuir 22: 7144-7147.

Duprat-de-Paule S, Guilbot J, Roso A, Cambos S, Pierre A. 2018. Augmented bio-based lipids for cosmetics. OCL 25(5): D503.

Herschel WH, Bulkley R. 1926. Konsistenzmessungen von GummiBenzollösungen. Kolloid Zeitschrift 39: 291-300.

Juncan AM, Morgovan C, Rus LL. 2019. Selection and application of synthetic versus natural emollients in the formulation of skin care products. Rev Chim 70(8): 2764-2768.

Kang L, Chen P, Wang B, et al. 2020. Cellulose nanocrystal dye as reinforcement matrix of lipstick for inhibiting color migration. Cellulose 27: 905-913.

Lecomte J. 2009. Les cires végétales : sources et applications. OCL 16 (4): 262-266.

Marangoni AG, Wesdorp LH. 2012. Structure and properties of fat crystal networks, 2nd ed. Boca Raton, FL: CRC Press.

Mi Lee C, Jin SP, Jin Doh E, Hun Lee D, Ho Chung J. 2018. Regional variation of human skin surface temperature. Ann Dermatol 31 (3): $349-352$.

Morikawa K, Matsushita S, Tomita A, Yamanami H. 2015. A real-life illusion of assimilation in the human face: eye size illusion caused by eyebrows and eyeshadow. Front Hum Neurosci 9(139): 1-9.

Mouloungui Z, Alfos C, Rossignol-Castera A. 2006. Utilisation des lipides non polaires dans les rouges à lèvres: état de l'art et perspectives. $O C L$ 13(5): 326-328.

Muto H, Ide M, Tomita A, Morikawa K. 2019. Viewpoint invariance of eye size illusion caused by eyeshadow. Front Psychol 10 (1510): 1-9.

Munawiroh SZ, Nabila AN, Chabib L. 2017. Development of water in olive oil (W/O) Nanoemulsions as lipstick base formulation. Int $J$ Pharm Med Biol Sci 6(2): 37-42.

Pan S, Germann N. 2019. Thermal and mechanical properties of industrial benchmark lipstick prototypes. Thermochimica Acta 679: 178332.

Rathke TD, Hudson SM. 2006. Review of chitin and chitosan as fiber and film formers. J Macromol Sci C 34(3): 375-437.

Cite this article as: Hubert C, Meriadec C, Panizza P, Artzner F, de Clermont-Gallerande H. 2020. Comparison between a wax/volatile oil mixture and vegetable butters in a long-lasting make-up formula: A rheological and structural study compared to product performance. $O C L$ 27: 42 . 